\title{
EDWARD JENNER: \\ THE HISTORY OF A MEDICAL MYTH \\ by
}

\author{
P. E. RAZZELL
}

Editor's Note: The provocative title of Mr. Razzell's article will doubtless shock many readers, but it is the duty of the historian to take nothing for granted and to put to the question periodically the major assumptions of history, just as it is an editor's duty to give space to iconclasts as well as to idolists. The following article is frankly controversial and the editor considered its implications so important, both for medical history and current practice, that he has invited Professor A. W. Downie, M.D., F.R.S., of Liverpool University, an acknowledged authority in this field, to comment on Mr. Razzell's arguments. The latter has claimed the right to reply to Professor Downie's criticisms and both comment and reply will be found at the end of the article. Discussion is now open to readers and any further discussion, by Professor Downie or others, will be published in forthcoming issues of Medical History. The editor confines himself to remarking that the October issue will contain an interesting account of smallpox in Ethiopia which may be read as an implicit refutation of Mr. Razzell's case. Despite the long-continued use of inoculation in this close community, epidemics of smallpox raged until Jennerian vaccination was introduced in the nineteenth century. If Mr. Razzell's article and the ensuing debate prove nothing else we are given a lively demonstration that medical history is by no means a dead subject but is concerned with issues which are very much alive.

F.N.L.P

THE purpose of this paper is to demonstrate that vaccination is a more attenuated form of the eighteenth century practice of inoculation. ${ }^{1}$ In a paper on eighteenth century population change, ${ }^{2} \mathrm{I}$ have argued that inoculation was effective in gradually eliminating natural smallpox, well before the advent of vaccination at the beginning of the nineteenth century. It is impossible to present the full evidence for this conclusion here, but only to illustrate it with selected statistics. ${ }^{3}$

Table I

Smallpox Mortality from Epidemics in Boston, Mass., U.S.A. in the 18th century ${ }^{4}$

\begin{tabular}{|c|c|c|c|c|c|c|c|c|c|}
\hline & $1677-78$ & 1702 & 1721 & 1730 & 1752 & 1764 & 1776 & 1788 & 1792 \\
\hline Population & 4,000 & 6,750 & 10,700 & 13,500 & 15,684 & 15,500 & & & 19,300 \\
\hline $\begin{array}{l}\text { Natural Smallpox } \\
\text { Cases } \\
\text { Deaths } \\
\text { Deaths per } 1,000 \text { cases }\end{array}$ & 700 & 213 & $\begin{array}{r}5,759 \\
842 \\
146\end{array}$ & $\begin{array}{r}3,600 \\
500 \\
139\end{array}$ & $\begin{array}{r}5,545 \\
539 \\
97\end{array}$ & $\begin{array}{l}699 \\
124 \\
177\end{array}$ & $\begin{array}{r}304 \\
29 \\
95\end{array}$ & $\begin{array}{r}122 \\
40 \\
328\end{array}$ & $\begin{array}{r}232 \\
69 \\
298\end{array}$ \\
\hline $\begin{array}{l}\text { Inoculated Smallpox } \\
\text { Gases } \\
\text { Deaths } \\
\text { Deaths per } 1,000 \text { cases }\end{array}$ & & & $\begin{array}{r}287 \\
6 \\
21\end{array}$ & $\begin{array}{r}400 \\
12 \\
30\end{array}$ & $\begin{array}{r}2,124 \\
30 \\
14\end{array}$ & $\begin{array}{r}4,977 \\
46 \\
9\end{array}$ & $\begin{array}{r}4,988 \\
28 \\
6\end{array}$ & $\begin{array}{r}2,121 \\
19 \\
9\end{array}$ & $\begin{array}{r}9,152 \\
179 \\
20\end{array}$ \\
\hline $\begin{array}{l}\text { Total Smallpox } \\
\text { Deaths } \\
\text { Deaths per } 1,000 \text { cases } \\
\quad \text { population }\end{array}$ & $\begin{array}{l}700 \\
175\end{array}$ & $\begin{array}{r}213 \\
32\end{array}$ & $\begin{array}{r}848 \\
79\end{array}$ & $\begin{array}{r}512 \\
37\end{array}$ & $\begin{array}{r}569 \\
36\end{array}$ & $\begin{array}{r}170 \\
11\end{array}$ & $\begin{array}{l}57 \\
10\end{array}$ & $\begin{array}{r}59 \\
6\end{array}$ & $\begin{array}{r}284 \\
10\end{array}$ \\
\hline $\begin{array}{l}\text { Left the town } \\
\text { Escaped disease in town } \\
\text { Had Smallpox before }\end{array}$ & & & & & $\begin{aligned} 1,843 \\
174 \\
5,998\end{aligned}$ & $\begin{array}{r}1,537 \\
519 \\
8,200\end{array}$ & & & $\begin{array}{r}262 \\
221 \\
10,300\end{array}$ \\
\hline
\end{tabular}

1 Throughout this paper inoculation is used to mean variolation (except where stated), as this was the term used by eighteenth century contemporaries, some of whose writings we shall be considering.

2 To be published in the Economic History Review.

3 None of the figures in this paper ought to be taken too literally, as there are many problems with 216 
Three important conclusions are to be derived from this table: (I) The smallpox death rate was reduced from 175 smallpox deaths per 1,000 living in 1677-8 to ten per 1,000 by 1792 , (2) this was achieved in spite of an increase in the virulence of the disease, (3) the reduced mortality may be directly attributed to inoculation, which protected the vast majority of the vulnerable population by the end of the eighteenth century.

An example of the effects of inoculation on smallpox mortality in England is to be found in eighteenth century Maidstone.

Table 2. Smallpox Mortality at Maidstone, Kent, $175^{2-1801^{5}}$

\begin{tabular}{|c|c|c|}
\hline Period & Smallpox burials & All burials \\
\hline $\begin{array}{l}\text { I } 752-6 \text { I } \\
I 62-7 I\end{array}$ & $\begin{array}{r}252 \\
76\end{array}$ & I 703 \\
\hline I $772-81$ & 60 & 154 \\
\hline $1782-91$ & 91 & 1676 \\
\hline $1792-1801$ & 2 & 2068 \\
\hline
\end{tabular}

A mass inoculation was conducted by Daniel Sutton in 1766 and its effects were described by Howlett in 1782 :

Upon casting an eye over the annual list of burials we see, that, before the modern improved method of inoculation was introduced, every five or six years the average number was almost doubled; and it was found upon enquiry, that at such intervals nearby the smallpox used to repeat its dreadful periodical visits ... in the short space of thirty years it deprived the town of between 500 and 600 of its inhabitants; whereas in the fifteen or sixteen years that have elapsed since that general inoculation it has occasioned the deaths of only about sixty. ${ }^{6}$

The main reason why most historians thought that inoculation had been ineffective against smallpox was the set of smallpox mortality statistics for London. These were faulty in several ways, ${ }^{7}$ but must be reinterpreted in the light of the fact that inoculation was utilized on a large scale much later in London than in the rest of the country, especially outside large towns. ${ }^{8}$ Howlett stated this quite explicitly in $178 \mathrm{I}$ :

regard to classification of disease, etc. However, smallpox is a sufficiently distinctive disease to enable us to use these figures as indicators of trends.

$4 \mathrm{~J}$. Blake, Public Health in the Town of Boston (Mass.), 1630-1822, Cambridge, U.S.A., 1959, p. 244. Royal Commission on Vaccination, 6th Report, Parl. Papers 1896/47, p. 762. H. R. Viets (Ed), $A$ Brief Rule to Guide the Common People of New England, Baltimore, 1937, p. 35. The figures in this table do not balance, as some people inoculated were not inhabitants of the town, and were therefore not included in the total population.

5 Figures compiled from the Maidstone Parish Register.

$6 \mathrm{~J}$. Howlett, Observations on the Increased Population... of Maidstone, Maidstone, 1782, p. 8.

7 For example no account is taken of the increased number of births.

8 The reasons for this are complex and it is not possible to analyse them here. 


\section{P. E. Razzell}

It may be thought, at first sight, that the healthiness of London is more increased than that of country towns. ... But it must be remembered that the diminished mortality in the latter appears to be chiefly owing to the salutary practice of inoculation, whereas in the former, for want of universality, it has hitherto been of little advantage. . . . In provincial towns and villages, so soon as this disease (smallpox) makes its appearance, inoculation takes place amongst all ranks of people; the rich and the poor, from either choice or necessity, almost instantly have recourse to it; and where 200 or 300 used to be carried to their graves in the course of a few months, there are now perhaps not above twenty or thirty. ${ }^{9}$

It is in the light of these findings that we must re-examine the relationship between inoculation and vaccination. One aspect of the conventional medical view of the relationship is that inoculation differs from vaccination inasmuch as it gives rise to pustular eruptions other than at the site of injection and is consequently a source of infection to an unprotected population. ${ }^{10}$ There is contemporary eighteenth century evidence to suggest, however, that this is not the case. None of the hundreds of incumbents making returns in the Statistical Account of Scotland at the end of the eighteenth century, specifies a case of inoculation spreading smallpox, which certainly would have happened had inoculation been infectious because of the partial inoculations of the gentry and farmers in some parishes. ${ }^{11}$

According to a letter sent from the Council of Geneva in $179 \mathrm{I}$ :

An epidemic of smallpox is of almost regular occurrence every five years, and between the epidemics it frequently happens that we have no natural smallpox whatever, little in the city or its vicinity. Inoculation began to be practised here in $175^{1}$, since which date we have inoculated a very large number of children annually, and with such marked success that the deaths have not exceeded $\mathrm{I}$ in 300 . Although we have often had to inoculate with pus brought from a distance at times when there was no smallpox to be found in the city, and although children so inoculated have gone freely into the streets, walks, and other public places, before, during, and after the eruption, we have never observed that they were sources of contagion, nor that they produced any intermediate epidemics, nor that they accelerated the return of the periodical epidemic. ${ }^{12}$

\section{An almost identical description was sent from the Hague:}

The 200 persons who were inoculated at the Hague, about the end of the year 1768 , without much regard to themselves or others, frequented all places of public resort; notwithstanding which no epidemic was produced, nor in the whole year did more than eight persons die of the smallpox, and of these three died in the spring, one by inoculation, and two by the natural disease, which they had caught at some other place and carried with them to the Hague, and the remaining five died towards the end of the year. ${ }^{13}$

\section{There were similar experiences noted at Chester ${ }^{14}$ and at Ware, Herts., ${ }^{15}$}

${ }^{9} \mathrm{~J}$. Howlett, An Examination of Dr. Price's Essay on the Population of England and Wales, Maidstone, 1781 , p. 94 .

10 The technical view of the relationship is that inoculation uses smallpox virus, whereas vaccination uses cowpox virus.

11 See Sir J. Sinclair (Ed.), The Statistical Account of Scotland, 21 vols., Edinburgh, I 791-99.

12 J. Haygarth, A Sketch of a Plan to Exterminate the Casual Smallpox, 1793, pp. 472-5.

13 Gentleman's Magazine, 47, 1777 , p. 224.

14 J. Haygarth, An Inquiry how to Prevent the Smallpox etc., Chester, 1 785, p. 588.

15 J. C. Lettsom, $A$ Letter . . . upon General Inoculation, i 778, p. I I.

218 
and many inoculators were well aware that their patients were not a source of contagion.

The most convincing evidence of the non-infectious nature of inoculation is provided by a series of experiments conducted during the late eighteenth century by Dr. O'Ryan, Professor of Medicine at the College of Lyons, France, part of which he described as follows:

I placed a person in the eruptive fever of the smallpox by inoculation at the distance of about half a yard from four children properly prepared; each exposure continued one hour, and was repeated daily for a fortnight, reckoning from the commencement of the fever till the pustules were become perfectly dry: not one of the four received the infection. Two months afterwards, I inoculated three of these children; they had the distemper in a very mild manner and recovered without difficulty. ${ }^{16}$

\section{O'Ryan concluded from his experiments}

that there is no risk of contracting it [smallpox], provided the person who is liable to the infection, keeps himself at a very little distance from patients in the smallpox, or from things which they have touched.17

Although we now know this view to be erroneous, we must still explain the results of his experiments.

A clue to the answer to our problem is to be found in Dixon's recent text on smallpox. In discussing the infectivity of scab virus he writes: '. . . in practise scab virus seems to lack epidemic potential. I have suggested (Dixon I948) that the virus extruded through the skin, perhaps modified by its passage, is in some way different from the virus from the respiratory tract.' ${ }^{18}$ Logically, the opposite also applies, i.e., the virus injected through the skin is also modified in some fundamental way. Therefore an inoculated person, whatever number of pustules erupt, would not be infectious, as all the smallpox viruses in his body would have derived from a stock of modified viruses which had been extruded through the skin of another person's body (the person from whom the virus was originally taken) and then passed through his own skin.

As the degree of infectivity of smallpox is probably connected with the degree of severity of the disease, ${ }^{19}$ we would expect the transmission of the virus through the skin to produce milder types of the disease. This is in fact what happens, as all the inoculators well knew. Mowbray, Gatti and the Suttons all produced much milder and safer results from inoculation by arm-to-arm transmission. Gatti ran into difficulty over his inoculation in 1765 of the Duchess de Bouffle, who had no pustular eruption except at the site of inoculation and suffered an attack of natural smallpox two and a half years later, ${ }^{20}$ a problem which would occupy the vaccinators forty years later. Gatti appears to have achieved these very mild results by taking the smallpox virus for his inoculations from the site of a previous inoculation, rather than from one of the pustular eruptions around the body. ${ }^{21}$

16 J. Haygarth, A Sketch of a Plan. ..., pp. 82, 83.

17 Ibid., pp. 78, 79 .

18 G. W. Dixon, Smallpox, 1962, p. 298.

19 Ibid., p. 298.

20 C. Creighton, The History of Epidemics, 1894, vol. II, pp. 495, 496.

21 A. Gatti, New Observations on Inoculation, 1768. 


\section{P. E. Razzell}

Fortunately, we have some experimental evidence on the degree to which smallpox virus can be attenuated. In 1777 John Mudge, a Plymouth surgeon, reported the following experiment:

Messrs. Longworthy and Arscott, surgeons, in the spring of 1776 , inoculated at Plymton, a neighbouring town, forty patients; of which number, thirty were injected with crude matter from the arm of a young woman, five days after she herself had been inoculated (i.e. from the site of inoculation before the eruption of pustules) with concocted matter (from a pustule around the body), which eventually did produce in her a pretty smart fever, and a sufficient number of eruptions. The other ten were inoculated with matter of another kind, which I procured, in a concocted state, from a pustule of the natural smallpox. The arm of all the forty patients took the injection; and the latter ten, after the eruptive fever, had the smallpox in the usual way. Of the other thirty, though the injection took place on their arms, so as to in flame them considerably, and to produce a very large prominent pustule, with matter on it, on each of them, yet not one of them had any eruptive fever, or a single subsequent eruption, on any part of the body. . . . It is to be remarked too that the matter which was in those pustules having been used to inoculate others produced on them exactly the same appearances, unattended also with either fever or smallpox. ${ }^{22}$

In other words it was possible to attenuate the smallpox virus to such an extent that only a single pustule was produced at the site of inoculation and this was achieved by taking the virus from the site of a previous inoculation. Adams repeated the same experiment at the beginning of the nineteenth century and was able to produce a whole series of cases in which there was only an eruption at the site of inoculation. He compared the latter with typical vaccine vesicles and claimed that they were identical. ${ }^{23}$ This was a conclusion confirmed by Guillou, who was also able to produce a typical vaccine vesicle at the site of inoculation. ${ }^{24}$ Dr. John Walker, Director of the Royal Jennerian Society, wrote to Lettsom in 1813 :

I have, from the first introduction of vaccination, after having observed its symptoms and progress, entertained an opinion respecting its native difference from those who suppose it a substitute only for the (inoculated) smallpox. ... Now I have from an early part of my practice, been in the habit of diluting the smallpox virus with water, previous to its introduction into the system [author's italics;] and in every instance I have then always found the disease mild, and the fever slight: this led me to the conclusion above hinted at. ... I believe the variola and vaccine (so called) to be, at bottom, the same disease, and could wish that the term variola mitior were employed instead. ${ }^{25}$

As Creighton observed, 'the very Director of the Jennerian Institute was among the prophets of the old inoculation'. ${ }^{26}$ However, from our present point of view what is significant is that Walker was able to produce the single local vesicle typical of vaccination, through a process of attenuating smallpox virus.

It is in the light of these neglected facts that we must reinterpret the history of vaccination itself. After a few initial experiments with cowpox in 1796 and

22 J. Mudge, $A$ Dissertation on the Inoculated Smallpox, 1777, pp. 20-22.

23 See Royal Commission on Vaccination, 4th Report, Parl. Papers, I89o-9r/44, p. 52.

24 Ibid., p. 53.

25 T. J. Pettigrew, Memoirs of the . . late John Coakley Lettsom, 181 7, vol. 3, pp. 350, 351.

26 Creighton, op cit., p. 590. 
I 798, Jenner's original vaccine lymph was lost, and it was not until the end of January I 799, when cowpox was discovered in Gray's Inn Lane by Woodville, that experiments were resumed. Woodville immediately sent Jenner some lymph to check its suitability. With this lymph, Jenner operated on twenty persons and reported to Woodville: 'Berkely, February I 799. The rise, progress, and termination of the pustules created by the virus were exactly that of the true cowpox.'27 Woodville was completely confused about the relationship between vaccination and inoculation, and later wrote: 'The virus which Dr. Jenner declared to be perfectly pure and genuine was taken from the arm of a (smallpox) hospital patient who had 310 pustules, all of which suppurated.' ${ }^{28}$ Woodville, who was a doctor at the London Smallpox Hospital, had found that a majority of 500 people vaccinated by him had pustular eruptions similar to those that took place during inoculation. The conventional medical explanation of this is that repeated recently by Dixon:

Unfortunately Woodville vaccinated his cases at the Smallpox Hospital, and at least twothirds of them showed some general eruptions. It is almost certain, that under these circumstances the patients were either inoculated (injected) with a mixture of vaccine and variola virus from contaminated lancets, were vaccinated and naturally infected with smallpox at the same time, or, in some cases, were vaccinated and then variolated from three to five days later, when they again had a double infection. ${ }^{29}$

This interpretation neglects a considerable body of evidence to the contrary, particularly that supplied by Jenner himself. At the beginning of 1800 he wrote a letter to Lord Egremont, one of his patrons, who had complained that some of the vaccine sent from London had produced pustular eruptions when used on his family at Petworth. Jenner wrote:

In many places where the (vaccine) threads were sent, a disease like a mild smallpox frequently appeared; yet, curious to relate, the matter, after it had been used six or seven months, gave up the variolous character entirely, and assumed the vaccine; the pustules declined more and more, and at length became extinct. I made some experiments myself with this matter, and saw a few pustules on my first patients; but in my subsequent inoculations (vaccinations) there were none. ${ }^{30}$

It is quite clear from this letter that the conventional medical explanation (e.g. Dixon's) of the pustular eruptions in Woodville's cases of vaccination is incorrect, for pustular eruptions occurred outside the London Smallpox Hospital where contaminated lancets, mixed injections or natural smallpox cannot be invoked as explanations (this is particularly true of Jenner's own cases). These pustular eruptions gradually disappeared as the new vaccine was transmitted from arm-to-arm, using the site of a previous inoculation. Thus the so-called vaccine was none other than smallpox virus, which was attenuated

\footnotetext{
27 William White, The Story of a Great Delusion, 1885, p. 147.

28 Ibid., p. 149.

29 Dixon, op. cit., pp. 119 , 120.

$30 \mathrm{~J}$. Baron, Life of Dr. Edward Jenner, 1827, vol. 1, pp. 314, 342.
} 
in a manner already familiar to some of the inoculators. The vaccinators were producing results similar to those produced by Arscott and Longworthy, Gatti, Adams and Walker, through taking smallpox virus from sites of previous inoculations and transmitting it from arm-to-arm; the only difference being that they thought that they had discovered a new process. Arscott, Longworthy and Mudge had rejected this attenuated technique which produced only a local pustule, as they felt it would give insufficient protection against future attacks of smallpox (in this they were right) and it was left to the vaccinators to utilize unknowingly the same technique twenty-four years later.

However, we must still try to explain what the relationship is between the cowpox and smallpox viruses. Unfortunately, the virologists do not seem to be in a position to settle this problem and it is not even agreed whether the one virus is autonomous of the other. ${ }^{31}$ According to one authority:

At the present day the general opinion agrees with that held by Jenner, that cowpox is simply smallpox much modified by passage through the cow. It might be supposed that this fact would be one easy of demonstration, and cows have by many observers, e.g. Woodville in 1799 , by Ceely, by Badcock, and by Thiele of Kazan in 1838, been experimentally inoculated with smallpox but in most cases the disease, when thus artificially produced in cows, appears to retain a considerable degree of virulence, and to produce general though slight symptoms when again communicated to human beings, instead of the purely local symptoms of ordinary vaccination. 32

Copeman attempted to explore the relationship between smallpox and cowpox experimentally:

He first inoculated a monkey with smallpox virus and then inoculated a calf from such an infected monkey. This resulted in typical vaccine, from which good strains of vaccine lymph were obtained. On the basis of this experience Copeman suggested that cowpox may actually have originated in the eighteenth century from inoculated smallpox, as the local sore produced by the inoculated incision frequently was very itchy, and milkers who scratched their arms may easily have conveyed infectious matter to the cow's udder. ${ }^{33}$

From our point of view the transmission of the smallpox virus through a cow or any other non-human animal, is an irrelevance, inasmuch as smallpox inoculation can be attenuated into vaccination merely by arm-to-arm transmission of the virus, using the previous sites of inoculation. This hypothesis is the only one to explain the manifold contradictions contained in all the evidence. $^{34}$

Does this conclusion mean that the reputation of Jenner is undeserved? He, who had been inoculated in the old method as a boy during the mass inoculation at Wootton-under-Edge in $175^{6}$, was an inoculator using the Suttonian method before he claimed to have discovered vaccination. ${ }^{35}$ The only advantage

31 Dixon, op. cit., pp. 119, 120, 163.

32 W. A. R. Thomson, Black's Medical Dictionary, 1963, p. 942.

33 G. Miller, The Adoption of Inoculation ... in England and France, Philadelphia, 1957, pp. 19, 20.

34 This includes the so-called phenomena of generalized vaccinia, which on the present hypothesis is nothing other than what eighteenth century contemporaries would have considered a typical inoculation. It would also explain why 'although vaccinia and cowpox have common features of wide host range, serologically variola is more closely related to vaccinia'. Dixon, op. cit., p. 163 .

35 J. J. Abraham, Lettsom, 1933, p. 192. 


\section{Edward Jenner: The History of a Medical Myth}

the latter had over the more traditional methods of inoculation was that it appeared to cause fewer direct deaths. The problem in evaluating this claim is that many deaths were attributed to inoculation, which were probably due to the fact that many people had caught smallpox before being inoculated. Thus for example, in Boston, Mass., inoculation was forbidden by law and was only allowed when the presence of an epidemic created such panic as to make it inevitable. As several thousand people were inoculated, some of them would have caught smallpox before being inoculated, and their subsequent deaths would be incorrectly attributed to the inoculation. In more controlled conditions the death rate from the mild Suttonian method of inoculation was virtually nil. The Sutton's claimed in 1768 'that about 55,000 had been inoculated by them since the year 1760 , of which number, six only had died'. ${ }^{36}$ Among the 5,694 people inoculated at the London Smallpox Hospital during the years I 797-9 there were only nine deaths. By the beginning of the nineteenth century the inoculators had attenuated their viruses sufficiently to be able to eliminate the risk of death altogether; for example Dr. Forbes, a supporter of vaccination and an opponent of inoculation, had to report that of the 2,500 people inoculated in the Chichester area in 1821 not one died. ${ }^{37}$ Inoculation had the advantage over the more attenuated vaccination of conferring a much longer period of immunity against future attacks of smallpox, and this was of course because of the larger numbers of antibodies produced. This much greater period of immunity was no mean advantage at a time when smallpox was such a constant threat.

Generally we must conclude that Edward Jenner's contribution to the history of medical innovation has been greatly over-estimated, and at most he was one of many innovators in the technique of inoculation against smallpox.

Comment by Professor A. W. Downie, M.D., F.R.S.

I have read through this paper carefully and it appears to me that the author has been very selective in quoting sources to uphold his thesis.

In his general proposition that the reduction in the smallpox death rate between 1677 and $179^{2}$ was due to smallpox inoculation, he has ignored the importance of other factors. It is true that the figures from Boston (Table $\mathrm{I}$ ) would appear to lend some support to his thesis, but he ignores the fact that in Boston very strict quarantine regulations were enforced to prevent the introduction of smallpox into that City. Isolation of cases when they occurred was strictly enforced. This and the quarantine regulations introduced to prevent the importation of smallpox into the town, were probably more important measures than inoculation in determining the diminution in incidence of the disease over the period covered in Table $\mathbf{I}$.

The author appears to believe that by the end of the eighteenth century

36 R. Houlton, Indisputable Facts, Relative to the Suttonian Art of Inoculation, Dublin, 1768, p. 10.

37 Dr. J. Forbes, 'Some account of the small-pox lately prevalent in Chichester and its vicinity', London Medical Repository, Sept. 1822, pp. $211-15$. 


\section{P. E. Razzell}

inoculation of smallpox was very widely and generally applied. This would seem very far from being the case. (Up to 1764 only 5,554 persons in the whole of Scotland had been inoculated with smallpox according to Alexander Monro Senior.) It is obvious from Haygarth's correspondence published in his Sketch (1 793) and in the letter to Percival of Manchester, that after the first few years of the introduction of inoculation against smallpox in Chester, the poor people in the town would not avail themselves of this measure. Indeed, he regrets that no-one had come forward at all for inoculation and that the poor preferred to acquire the disease in the natural way. With reference to the diminution of smallpox as a result of inoculation towards the end of the eighteenth century, he states that in 1774 only $1 / 14^{\text {th }}$ of the population of Chester had not suffered from the disease. This was at the time when inoculation of the smallpox was not available to the poorer people in the town. Similar observations were made in Leeds and Newcastle. So much for the author's suggestions that inoculation had greatly lessened the ravages of smallpox by the end of the eighteenth century! It seems much more likely that the diminished mortality from the disease at this time was due to the recognition of the infectious nature of the disease and measures of isolation being introduced to prevent its spread, such as the provision of isolation wards in hospitals and isolation of patients at home, together with improved housing and nutrition of the poor.

The author also quotes reports apparently showing that the inoculated disease was not infectious. This, however, is not supported by evidence from other sources. Maitland recorded in 1722 that the little girl, Mary Batt aged two years, who was inoculated by himself, infected six domestic servants with typical smallpox from which one of them died. It is also apparent from Haygarth's Sketch ( I 793) that the disease was frequently spread from inoculated to susceptible persons. Indeed, it was an essential part of Haygarth's plan that those inoculated with smallpox must isolate themselves at home to avoid spreading infection. He quotes several instances where such spread did in fact occur. The author of the manuscript has made selections from the letters published in Vol. II of the Sketch, choosing those purporting to show that the inoculated disease was not infectious. He has ignored other letters in the same volume which provide evidence of spread of infection from inoculated persons. He also ignores the fact that even the casual smallpox is not as highly infectious as many people think-a point also stressed in all Haygarth's writings.

There is evidence from the observations of the Suttons, Dimsdale and others, that the introduction of the Suttonian technique, of taking material from the site of inoculation of the smallpox after four or five days for further inoculations, produced a milder type of inoculation smallpox than had previous practice. When this technique was followed the mortality from the inoculated disease became much less than in the earlier years ( $1721-30)$, but even at the end of the eighteenth century most authorities agreed that the mortality from inoculated smallpox was still of the order of $1 / 200$ to $1 / 500$.

The author's main contention that the vaccinia virus now employed has been derived from smallpox virus attenuated by repeated passage through arm 
vaccination, may be true, but proof of this is not available at the present time. The strains at present in use for vaccination have been so long passed in laboratory animals that the history of their origin is uncertain. It has, however, I think been established from Jenner's experiments and those carried out with fresh stocks of cowpox in I 799, that cowpox infection did protect against smallpox. It is true, as Dixon has maintained, that Woodville's experiments were unreliable in that his inoculations of cowpox were carried out in a smallpox hospital and many of the subjects were subsequently tested by variolation a few days later. These two facts made it very difficult to be sure that Woodville's observations had much bearing on the value of cowpox virus as an immunizing agent. It is, however, also clear from the observations of Ceely, published from 1839 onwards, that inoculation of genuine cowpox virus would protect against smallpox. Ceely gave very clear descriptions of the effects of inoculating cowpox virus on humans and, indeed, isolated fresh stocks of virus from the natural disease in cows or persons infected from them. In my opinion, Dixon's comments on Woodville's work are quite justified.

The author mentions the adaptation of smallpox virus to propagation in the cow. Many such observations of this kind were recorded in the nineteenth century but they are all of doubtful value because cowpox was sometimes inoculated on the same animals and the later experiments were carried out (e.g. Copeman's) with variola virus in institutes where strains of vaccinia were also in use. French workers showed many years ago that vaccinia virus spread very readily amongst cows and suggested that many of the reported successful inoculations with variola in cows were, in fact, cross infection of the animals with strains of vaccinia in use in the same establishments. All recent attempts (in the last twenty-five years) to infect cows with smallpox virus and to pass the virus to successive animals, have failed, even when the monkey has been used as an intermediate host. (Our own attempts to convert variola to vaccinia by inoculation of animals have been completely unsuccessful.) (See also Herrlich et al. Arch. ges. Virusforschung, 1963, 12, 579.)

We have no doubt that cowpox is a natural disease of cattle and is not derived from variola. We have isolated at least a dozen strains of cowpox virus from the natural disease of cattle or from lesions on the hands of those working with infected animals. All these strains of virus are quite different from strains of variola virus and also from current strains of vaccinia virus. However, these strains of cowpox virus are immunologically practically identical with vaccinia virus and with variola virus. Immunisation of animals with cowpox virus produces antibody which is apparently effective against variola and vaccinia viruses. Our cowpox strains have the same host range as vaccinia strains and can be readily passed on to a variety of laboratory animals. This feature is not shown by a number of strains of variola virus which we have tested in this way.

I apologize for writing to you at such length, but I cannot agree with much of the argument in the enclosed manuscript. The author has selected to support his thesis only such evidence as would suit his purposes and has neglected many other works which would appear to refute his arguments. 


\section{P. E. Razzell}

\section{Mr. Razzell's reply}

I will deal with Professor Downie's points in the order that they were raised. He writes: 'This (the isolation of smallpox cases) and the quarantine regulations taken to prevent the importation of smallpox into the town, were probably more important measures than inoculation in determining the diminution in incidence of the disease over the period covered by Table I.' Yet if you look at Table I you will see that the numbers escaping the disease in and out of town amount to only 483 people out of a total population of 19,300 in 1792 . Table I indisputably demonstrates that the diminution in the number of smallpox deaths may be directly attributed to the effects of inoculation.

The second point raised concerns evidence for the hypothesis that inoculation did spread natural smallpox to an unprotected population. Maitland's example of an inoculated two-year-old girl spreading the disease to six domestic servants is cited. This incident occurred in 1722 when the English inoculators invariably used natural cases of smallpox as the source of their virus. As Dixon has written:

In spite of the warnings in the earlier writings of the desirability of sending someone else to collect the smallpox matter so as to avoid injecting the inoculated person simultaneously with the natural disease (from respiratory virus on clothing, or in other ways from an infectious patient), it seems clear that Armyand as well as Maitland did not realize the effect of inoculating simultaneously with, or after contact with, natural smallpox in confusing the statistics of inoculation. 38

The standard practice of later inoculators was to take smallpox matter from previously inoculated cases or to carry it with them dried on threads, thus avoiding the problem of transmitting the infection from natural cases. Even if we reject Dixon's point, Maitland's example of the danger of inoculation is very suspect, because many cases of natural smallpox were to be found in London every week of every year during this period (see the London Bills of Mortality) - therefore it is quite possible for the domestic servants to have caught the disease naturally from another source. A much better type of evidence is that referring to a situation where a partial inoculation takes place in an isolated rural area in response to the threat of an epidemic. In the twenty-one volumes of the Statistical Account of Scotland many of the incumbents described the recent history of diseases in their parishes-of the 234 incumbents who mentioned that inoculation has taken place in their parishes not one specified an instance of it spreading the natural disease to vulnerable members of the population. An even more convincing example of this point is supplied by Dr. John Forbes (a supporter of vaccination and an opponent of inoculation), who in his description of the smallpox epidemic of 1821 in the Chichester area had to admit that

during the winter months he (a local inoculator) inoculated upwards of 1,000 persons (around the country area outside Chichester) ... not more than 130 or 140 cases of natural smallpox

38 C. W. Dixon, Smallpox, 1962, p. 232. 


\section{Edward Fenner: The History of a Medical Myth}

were witnessed by all the surgeons during the course of the epidemic. Of these, by far the greater number occurred in Chichester, owing to the continued resistance of the surgeons to inoculate. ${ }^{39}$

Professor Downie goes on to point out Haygarth's belief in the contagiousness of inoculation. All contemporaries believed that inoculation spread smallpox, inasmuch as they believed it to be itself a mild form of natural smallpox. However, when it came to a question of empirical evidence rather than theoretical belief, there is no doubt about the conclusion to be drawn. Haygarth himself concluded in $178 \mathrm{I}$ from his experience in Chester that

Inoculation did not, as some might apprehend, spread the contagion, but appeared to produce a quite contrary effect. For in the districts where most patients were inoculated, there remained the fewest in the natural smallpox, and, in the districts where the smallest number were inoculated, the distemper was afterwards most general.40

The most conclusive evidence for the non-contagious nature of inoculation is the series of experiments by O'Ryan which were quoted in the text of my paper, as well as the fact that the early 'vaccines' were directly derived from smallpox viruses without transmission through a cow (e.g. Walker's 'vaccine') and yet nobody has ever suggested that such 'vaccines' spread natural smallpox.

According to Professor Downie the Suttonian technique consisted 'of taking material from the site of inoculation of the smallpox after four or five days for further inoculation'. This was not the case-the Suttons took their material from any pustule around the body and not just from the site of inoculation; they also took their material from pustules at every stage of development. ${ }^{41}$

The essence of their technique was the use of a lancet, making the lightest of scratches and inserting the minimal amount of material. As for the mortality from inoculation, it is very difficult to assess independently of mortality due to natural smallpox before inoculation had time to take effect. As I have already indicated, in the controlled conditions of the London Smallpox Hospital its mortality was negligible, particularly in the later period-e.g. of the $43 \mathrm{I}$ in-patients inoculated between 1808 and 1813 not one died. ${ }^{42}$ Pearson, one of Jenner's chief supporters, conceded that the mortality from inoculation was neligible and quoted two examples:

Dr. William Heberden informs me, that at Hungerford, a few years ago, in the month of October, 800 poor persons were inoculated for the smallpox, without a single case of death. No exclusion was made on account of age, health, or any other circumstances, but pregnancy; one patient was eighty years of age; and many were at the breast, and in the state of toothing. Dr. Woodville acquaints me, that in the current year ( 1798 ), from January to August inclusive, out of 1,700 patients inoculated at the Inoculation Hospital, including the in and out patients, only two died, both of whom were of the latter description. ${ }^{43}$

\footnotetext{
39 Forbes, op. cit., pp. $213,215$.

40 Haygarth, An Inquiry. ..., p. 188.

41 R. Houlton, Indisputable Facts Relative to the Suttonian Art of Inoculation, Dublin, 1768, p. 40.

$42 \mathrm{~J}$. R. Hutchinson, 'A historical note on the prevention of smallpox in England', Health Annual Reports (Ministry of Health), 1945-46. Appendix A, p. 122.

43 G. Pearson, An Inquiry Concerning the History of the Cow Pox, 1798, p. 79.
} 


\section{P. E. Razzell}

It should also be remembered that Walker's 'vaccine' which was the one most widely used in early nineteenth century England, was in fact diluted and attenuated smallpox virus - and it gave rise to a negligible rate of mortality.

I have not disputed the power of cowpox to protect against smallpox, but have argued that vaccinia was directly derived trom smallpox. Professor Downie counters this point by stating that it has been impossible during the past twenty-five years to infect cows with smallpox virus, i.e. produce cowpox from smallpox. He suggests that the very many previous successes in doing this were due to 'cross infection of the animals with strains of vaccinia in use in the same establishments'. This argument is implausible in the light of the fact that the purpose of trying to infect cows with smallpox was not experimental, but was an attempt to produce vaccinia which was otherwise not available. Vaccines were difficult to maintain and acquire, hence the attempts to produce them 'artificially'. ${ }^{44}$ This being so it is highly unlikely that vaccinia was present in these establishments. If 'cowpox is a natural disease of cattle' why is it not to be found in New Zealand where there is little or no smallpox and vaccination, and why do not cases of human cowpox arise in slaughterhouse workers? As Dixon has said: 'This would suggest that cowpox is not a natural disease of bovines. ${ }^{45}$ Cowpox appears to have increased considerably with the advent of inoculation in the eighteenth century and declined during the nineteenth and twentieth centuries when inoculation disappeared and the amount of vaccination diminished. This would suggest that Copeman was right in thinking that for smallpox to be suitable for adaptation to the cow it must be taken from an inoculated rather than a natural case (it should be noted that there were several mass inoculations in Gloucestershire at about the time that Jenner discovered his first cases of cowpox, e.g. in 1795 at Berkeley and at Dursley in I 797 when over I, IOO people were inoculated). However, for the purposes of my paper it is not necessary to demonstrate that cowpox derives from smallpox, but merely to show that the early 'vaccines' were directly derived from smallpox without using an intermediary host such as the cow, and that this is indisputable is demonstrated by the fact that Walker admitted it to be so.

As for Professor Downie's last point about inoculation not being very widespread at the end of the eighteenth century, I have dealt very fully with this question in the paper to be published in the Economic History Review. In fact the best evidence is to be found in the writings of Jenner and his early supporters, e.g. Jenner wrote: '. . . the common people were rarely inoculated for the small-pox, till that practice was rendered general by the improved method introduced by the Suttons. . . . 46 These early writings are full of references to mass inoculations, and most of Jenner's cases of people with natural cowpox had been inoculated at some time during their lives. Professor Downie takes the experience of the towns as typical for the country as a whole, but only a small minority of the total population lived in such towns. In a country village

44 See for example J. Jones, Vaccination, Louisiana, Baton Rouge, 1884, pp. 401-3.

45 Dixon, op. cit., p. 162.

46 The Medical Repository, New York, 1802, vol. 5, p. 239. 


\section{Edward Jenner: The History of a Medical Myth}

or market town epidemics of smallpox were very infrequent, sometimes occurring only every twenty or thirty years. When such an epidemic did occur it struck such a large proportion of the total population (children and adults) and was so virulent (lack of a pool of antibodies) that the resulting panic drove everyone to be inoculated, e.g. when an epidemic broke out in Blandford, Dorset, in I 766 'a perfect rage for inoculation seized the whole town'. ${ }^{47}$ In a place like Chester only a fourteenth of the population (all infants) had not suffered from smallpox, because it was virtually endemic, i.e. in the town nearly every year. This bred a fatalistic attitude amongst the parents of poor children, particularly as the piecemeal nature of smallpox mortality did not lead to a spectacular demonstration of the effects of inoculation as it did in the country areas. Inoculation was virtually universal in such areas by the end of the eighteenth century and was also making rapid headway in the large towns by that time.

It is true that only 5,553 persons were reported to have been inoculated in Scotland by I 764 , but inoculation made much greater progress in England than Scotland (200,000 inoculations were reported to have taken place in England by 1766 ). The great watershed in the history of inoculation was the popularization of the Suttonian technique from about 1768 onwards; the Suttons alone inoculated 245,000 people in the nine years between 1768 and 1777 . Although the spread of inoculation continued to lag in Scotland in comparison with England, of the 243 incumbents who discussed it in the Statistical Account of the 1790 , 162 said that it was widely practised in their parishes, ${ }^{48}$ as against ninety-one who said that it had still to become general.

Perhaps what we now know about inoculation could be put to some practical use. Many tens of thousands of people die of smallpox each year in the world. This is partly due to inadequate medical facilities and the difficulty of obtaining vaccine in very isolated, primitive areas. It is just in such areas that inoculation would be most useful. Rosenwald has recently described mass inoculations amongst tribal Africans in Tanganyika - the operation appears to have been both safe and effective. ${ }^{49}$ Undoubtedly some form of further observation or possibly even experimentation is necessary before smallpox inoculation can legitimately be used in certain special and limited circumstances.

47 C. Creighton, The History of Epidemics, vol. II, 1894, p. $5^{1} 3$.

48 For example the incumbent of Duirinish, Skye, wrote in 1792 : 'this increase in population may be attributed ... above all, to the inoculation of the smallpox, which has been universally practised in this island for thirty years past, and has been the means of preserving many lives.'

49 C. D. Rosenwald, 'Variolation', Med. Offr., I951, 85, 87. 